\title{
COCENTAINA EN EL PERÍODO ISLÁMICO: POBLAMIENTO Y GEOPOLÍTICA
}

\author{
Francisco FRANCO SÁNCHEZ \\ Estudios Árabes e Islámicos (Universidad de Alicante)
}

\section{INTRODUCCIÓN.}

El Profesor Juan Manuel del Estal ha estudiado en numerosos y documentados trabajos la sociedad cristiana peninsular y sus avances territoriales a costa de Al-Andalus; por todos son conocidas sus aportaciones tanto al conocimiento documental, como al de las sociedades que generaron tal documentación. Invitado a sumarme en su merecido homenaje, como arabista he considerado interesante aportar la perspectiva de la evolución histórica de una comarca montañosa del interior de a provincia de Alicante, Cocentaina.

En bastantes de sus trabajos, el profesor del Estal se ha centrado sobre la dinámica de la conquista castellana o catalano-aragonesa. Por ello hemos pensado estudiar las noticias en que las fuentes árabes y romances hablan de esta comarca del interior, para mostrar -en lo posible- cuál fue la evolución de esta comarca a lo largo de la historia andalusí, y en los momentos antes y después de la conquista cristiana. 
Desde tiempos inmemoriales Cocentaina ha sido una importante población situada en el ámbito montañoso del interior de la actual provincia alicantina. Se han conservado algunos restos que apuntan un temprano origen histórico de la población, ya mucho antes de la llegada de los musulmanes a la Península, pero escasean las noticias que nos hablan de ella antes de la conquista catalano-aragonesa. A pesar de ello, todos los datos obligan a concluir que Cocentaina fue una importante urbe en el período islámico.

El castillo de Cocentaina, hoy apenas una sombra de la construcción original islámica, es una muestra de los importantes restos de la arquitectura militar musulmana de la comarca. Según parece, la cronología de los hallazgos cerámicos del mismo se remonta, al menos, hasta el siglo $\mathrm{X}, \mathrm{y}$ probablemente al IX.(1) Los otros castillos de la comarca, que en tiempos estaban conectados visualmente con él, son también mudos testigos de la historia del periodo musulmán. Numerosas edificaciones, torres $y$ atalayas formaban entonces una red de control de los caminos y las comunicaciones en toda el área de la montaña alicantina. Esta red de fortalezas y atalayas desempeñaron un papel de primordial importancia en la época de la conquista y subsiguiente período mudéjar, con las revueltas de Al-Azraq y de los grupos de musulmanes llegados no ha mucho a las comarcas de la montaña interior alicantina.(2)

Las otras noticias que conocemos son las que aparecen en las obras escritas del período islámico o en la documentación posterior a la conquista. El panorama que nos presentan de la historia de Cocentaina en la época islámica es desigual y con numerosas lagunas. Desigual porque ha habido un gran desarrollo de la investigación sobre ciertos aspectos o épocas de esta historia, en detrimento de otros temas. Como mero ejemplo se pueden aducir la atención que se ha dedicado a los hechos relacionados: con el Cid y la conquista del castillo de Benicadell;(3) los numerosos estudios que se han centrado en el estudio de los mudéjares contestanos, (4) o la atención prestada a las revueltas de Al-Azraq. (5)

Pero, a pesar de la atención centrada en el último período del dominio islámico y en los musulmanes que se quedaron tras la conquista catalanoaragonesa, la historia anterior de la Cocentaina islámica tiene aún lagunas. Seguidamente presentamos el panorama que las fuentes árabes diversas esbozan de esta comarca, teniendo en cuenta las últimas investigaciones, y siguiendo la pauta que en su día marcó M. de Epalza.(6) 


\section{COCENTAINA EN LAS FUENTES ESCRITAS ÁRABES.}

Son contadas las citas de los textos árabes que nos ayudan a reconstruir el pasado islámico de Cocentaina. Generalmente se trata de menciones relacionadas con algún perosonaje notable, de quien se afirma que era de Cocentaina o estuvo en ella, añadiendo en pocos casos algún dato más. I. Cinco son los principales autores árabes que mencionan a la ciudad de Cocentaina. Cronológicamente, el más antiguo es $\mathrm{Al}-{ }^{\mathrm{C}} U \underline{d} \mathbf{r}$, nacido en Dalías (Almería) en 393/1002.3 y muerto en la capital almeriense en 478/1085.6. Su obra $\operatorname{Tarss}^{\bar{\tau}}$ al-ajbăr es importante por su antigüedad, por la gran cantidad de datos en ella contenidos, y porque el autor demostró conocer muy bien las tierras del Šarq Al-Andalus. Menciona en esta obra geográfico-histórica a Cocentaina como Qustāniya (errata en la transmisión del nombre que se puede corregir como Qusian]tāniya), un ŷuz' (o sector) dependiente de la Küra (provincia) de Valencia;(7) este $\hat{y u z}$ ' es citado junto con los de Ollería, Albaida, Gallinera, Cullera, Alcira, Xàtiva, Benicadell y otros tantos de difícil identificación. Cocentaina limitaría con los âyzā' de Gallinera, Albaida y Benicadell.

II. El segundo autor que hace referencia a la población es Yāqūt AlHamawi, geógrafo oriental nacido en los dominios bizantinos del Asia Menor en 575/1179.80, converso al Islam y muerto en Alepo en 626/ 1228.9. Su obra $M u^{c} \hat{y} a m$ al-buldān es un repertorio enciclopédico de lugares ordenados alfabéticamente; de cada uno de ellos se aporta su ubicación geográfica, algunos datos descriptivos y se recogen los personajes famosos originarios del mismo. En esta enciclopedia hay una entrada dedicada a Qusantāna, hisn del ${ }^{c}$ amal (distrito) de Denia, como lugar del que era originario Abū I-Ẃalíd Ibn Jamīs, apellidado Al-Qusantānī ("el de Cocentaina"), ministro de la Taifa de Denia.(8)

III. El tercero de los autores árabes que citan esta ciudad es lbn AlAbbār, valenciano nacido en 595/1198.9, que hubo de emigrar a causa de la conquista cristiana y murió en su exilio de Túnez en 658/1260. Escribió varios repertorios biográficos en los que recoge noticias de personajes ilustres de origen valenciano, que residieron o pasaron por Valencia, o que destacaron como literatos. En su repertorio llamado Takmilat li-Kitāb as-sila hace numerosas menciones de Cocentaina, añadiendo en ellas por lo común "del camal (distrito) de Denia». Unas veces para hablar de dos de los miembros de la familia del magistrado Ibn Jamis, mientras que otras alusiones a Cocentaina las hace al referir las tres biografías de la familia de los Sid Bono de Guadalest.(9) De todos ellos hablaremos más adelante con detalle. 
En otro de sus repertorios biográficos, conocido por $A /-M u^{c} \hat{y} a m$ vuelve a citar Qusantāniya como patria de la que era originario Abū 'Āmir Ibn Jamis (m. 543/1148.9(10)

IV Lisān Ad-Dín Ibn Al-Jatỉb es el cuarto escritor árabe que cita a Cocentaina. Cronológicamente es más tardío (pues nació en Loja en 713/ 1313.4 y murió en Fez en 776/1374.5). Cita la ciudad de Cocentaina al hacer referencia a la familia de los Banū Síd Bona $y$ a su importante cofradía religiosa (tarīqa), asentada en el barrio del Albaicín de Granada. Aparece esta mención en su famosa obra, la Al-Ihātat fi ajbār Garnāta, repertorio de biografías de personajes ilustres granadinos, o de cualquier otra procedencia pero que vivieron o pasaron por la Granada en la época nazarí.(11)

V. La última de las referencias es la que hace Al-Maqqarī, tardío escritor e historiador árabe (nació en Tlemecén en 998/1589.90 y murió en el Cairo en 1041/1631-2). Es el último gran cronista de la historia de AlAndalus, pues se dedicó a recoger en su obra histórica las más diversas noticias de la misma. Toma de lbn Al-Abbār la biografía del más famoso de la saga de los Síd Bono/a, haciendo entonces mención de Qusantāniya, «del distrito ('amal) de Denia». Este notable de la familia de los Síd Bono afirma que era "de la gente de Cocentaina (min ahl Qustatāniya)», enfatizando su calidad de centro urbano y su característica de ser la capital administrativa de la región.(12)

Todas estas referencias comprenden dos grupos temáticos, o tratan de dos temas esenciales: en uno primero se menciona a los musulmanes ilustres y famosos relacionados con la ciudad, mientras que un segundo grupo de noticias aluden a la propia Cocentaina y su relación administrativa con la Cora de Valencia o el camal de Denia.

Aunque puedan parecer escasas las noticias, de un minucioso estudio de cada una de ellas y de una comparación de las mismas con otras fuentes árabes pueden extraerse una serie de conclusiones cuya importancia excede de las escuetas alusiones de los cinco autores referidos. En los siguientes epígrafes se tratarán separadamente cada uno de estos dos grupos de noticias, dedicándole especial atención a los personajes ilustres de la Cocentaina árabe. 


\section{CONTESTANOS ÁRABES ILUSTRES.}

Entre los personajes ilustres que los autores árabes nos refieren como procedentes de la Cocentaina musulmana se destacan dos familias y un tercer grupo de personas notables que pasaron o residieron en la población.

\subsection{La familia de los Banū Jamís.}

En primer lugar hay que mencionar la familia de los Banū Jamīs, que desempeñaron importantes cargos públicos en Denia, Valencia y Xàtiva en los siglos XI al XIII, especialmente cargos relacionados con la judicatura.

Los omeyas desde el s. IV/X propiciaron una planificada labor de profundización en la islamización de las poblaciones del levante penisular, como uno de los medios para detener las tentativas de infiltración religiosa (y política) en Al-Andalus de la vecina dinastía shiíta fatimí de Túnez. Consecuencia de este interés islamizador fue el gran número de especialistas en teología islámica, derecho musulmán y ciencias religiosas en general que surgieron de las ciudades del Šarq Al-Andalus; en especial desde el s. V/XI en las taifas de Denia y Murcia. En la Taifa de Denia (de la que dependió el territorio de Cocentaina), su gobernante, Muŷāhid Al-c'Āmiñ̄, y su hijo, 'A $A$ I lbn Muŷāhid, destacaron por su mecenazgo de científicos, literatos, juristas, teólogos y sabios en las diversas ramas de la religión islámica. (13)

No es de extrañar que unos ilustres contestanos, como los Banū Jamis, acudieran a completar su educación superior a la Denia taifal, y llegaran a destacar como jueces de importantes ciudades levantinas como Denia, Valencia o Xàtiva. El primero de los Banū Jamîs conocidos fue Abū I-Wa Tî̀ Ibn Jamīs, de quien Yãqut afirma fue visir de Muŷāhid Al${ }^{\mathrm{A}} \overline{\mathrm{A}} \mathrm{mi} \overline{\mathrm{T}}$ (m. 436/1044.5).(14)

Pariente del anterior fue $A b \bar{u}{ }^{c} \bar{A}$ mir Muhammad Ibn IsmāTी Ibn Muhammad Ibn 'Abd Al-Malik Ibn ${ }^{C} A b d$ Ar-Rahmān Ibn Umayya

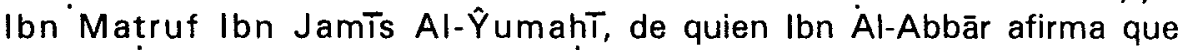
era "min ahl Qustantāniya "amal Dãniya»; nos informa de su largo curriculum de estudios $y$ de sus maestros en diversas ciencias de la religión, en Murcia y Córdoba; que "escribió para los jueces de Xàtiva y Valencia»; fue doblemente versado en cuestiones jurídicas (masā in y en contratos ('aqd aššsurüt), de buena caligrafía, cualificado (mutasrrifan) en cuestiones de ãdab. Murió en 543/1148.9.(15)

De Abū 'Āmir Muhammad Ibn IsmāT Ibn Muhammad Ibn IsmāTT Ibn Jamīs Al-Ŷumahī nos dice Ibn Al-Abbār que era "min ahl Qusantāna camal Dāniya». Fue cadí en Valencia durante la fitna, alfaquí, 
adīb, afortunado poeta, calígrafo(16), conocedor de los ahkām, experto en contratos ('aqd aš-šurüt), buen calígrafo, persona recta y célebre. Desde Valencia emigró a Xàtiva, donde también ejerció el cadiazgo. Pasó luego a Sevilla, en el año 626/1228.9 y murió en Xàtiva en safar del $639 / 1241 \cdot 2 .(17)$

No poseemos más datos sobre la vida de los miembros contestanos de la saga, pero el propio Ibn Al-Abbār nos habla de otros dos personajes de la misma, uno originario de Valencia (que muere en Argel, en 547/1152.3 ó 548/1153.4)(18) y otro de Almería (que falleció en Alejandría después del 596/1199.1200).(19) M. de Epalza ha apuntado la posibilidad de que el famoso poeta Ibn Jāmis de Tlemecén fuera uno de sus descendientes dos siglos después, ya que su apellido familiar fue escaso en la onomástica árabe andalusí.

\subsection{La familia de los Banū ST̃d Bono.}

\subsubsection{Los Banū Síd Bono, en el Šarq Al-Andalus.}

La segunda familia de personajes musulmanes ilustres relacionados con Concentaina es la de los Banū Síd Bono. Es de los pocos linajes del que tenemos bastantes datos sobre sus miembros desde el siglo $X$ al $X V$, lo cual nos permite seguir la evolución de esta importante saga a lo largo de la propia historia de Al-Andalus. (20)

1. El primer personaje de la saga es conocido por su lápida sepulcral, hallada en Benimaclet (localidad cercana a a la ciudad de Valencia) y publicada en 1928 por Julián Ribera.(21) Se trata de Muhammad Ibn ${ }^{c}$ Abd Allāh Ibn Sî́d Bono Al-AnsāriT, fallecido en Valencia el $1^{\circ}$ de ŷumādà / del 453 (24 de mayo del 1061). Es del único Síd Bono del que poseemos evidencia epigráfica o material, puesto que el resto de los miembros de la familia únicamente son conocidos por las noticias que proporcionan las diferentes fuentes árabes escritas.(22)

2. El segundo miembro identificado de los Síd Bono (el primero que citan las fuentes) es Ahmad Ibn Yahyà Ibn Síd Bunuh (Bono) Al-ŶyzāT, A bū $\hat{Y} a^{c} f a r$, de quen Ibn Al Abbär dice era "min ahl Qustantāniya, 'amal Dāniya", siendo el primero de la saga que tenemos ubicado ya en Cocentaina; dice que tomó tradiciones de Abī 'cATi IsmāT lbn Muhammad Ibn Sufyān, y a su vez las transmitió a su hijo Abū Bakr Yahyà Ibn Áhmad. No expresa la fecha de la muerte, pero, en relación al óbito de éste debió morir en torno a la década del 550/1155.(23)

3. Hijo del anterior, Yahyà Ibn Ahmad Ibn Yahyà Ibn Síd Bono AlJuzāT, de kunya Abū Zakariyyā' y Abū Bakr, según las fuentes árabes nació "min Qustantāniya camal Dãniya" -como de hecho se seguirá diciendo para el resto de miembros de esta familia- en el primer tercio del siglo 
VI/XII. Estudió las lecturas coránicas también con el deniense Gulām AlFarās. Además de su actividad como tradicionalista ejerció el cargo de lector coránico (muqrī') en la pujante y vecina Denia. En 578/1182.3 inicia su peregrinación a La Meca; estudió un tiempo en Almería (donde tuvo ocasión de conocer las Magamāt de Al-Hariñi), antes de viajar a Alejandría, donde recibirá las enseñanzas de grandes sabios. Tornará a su tierra de origen, siendo el primero en las lecturas coránicas y tomando discípulos en Denia. Muere en el 590/1194.(24)

4. El tercer personaje citado por las fuentes árabes es Hasān Ibn Ahmad Ibn Yahyà Ibn Sīd Bono Al-JuzāT, Abū ${ }^{\mathrm{C}} A$ Tî. El único dato conocido de él es que recibió tradiciones y enseñanzas coránicas de su hermano Yahyà Ibn Sĩd Bono $\left(n^{\circ} .3\right)$. Estas enseñanzas coránicas las transmitirá él mismo a su hijo Gālib ( $n^{\circ}$. 6).(25)

5. El quinto de la saga es $\hat{Y} a^{C} f a r ~ I b n{ }^{c} A b d$ Allāh Ibn Muhammad Ibn

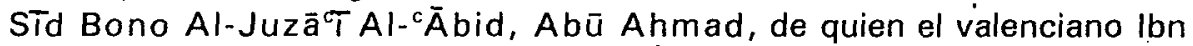
Al-Abbār dijo que su origen era «min ahl Qustantāniya camal Dāniya». El cadí granadino An-Nubāhī precisa que un antepasado suyo había fijado su residencia en Wãdi Lašt, Guadalest.(26) Nació, como el resto de su familia en Zanīta, y estudiará tradiciones coránicas en la ciudad de Valencia con los mejores maestros contemporáneos. Durante su viaje de Peregrinación a La Meca hará escala en Bugía, y allí trabará amistad con el maestro sufí Abū Madyan(27), que influirá profundamente en él; en Alejandría también recibirá las enseñanzas del gran maestro suf́́ As-Silafí. Tras estos contactos, le quedó honda huella en el espíritu. A partir de entonces comenzó a manifestar una larga serie de carismas místicos, acudiendo la gente a él en masa para recibir su beneficiosa baraka.(28)

Con posterioridad a su encuentro con As-Silafi 29) realizó un largo viaje, a cuyo regreso se detuvo en Granada y oró en una de sus rábitas; después de este hecho, esta rábita granadina se convertirá en lugar santo para sus seguidores. Tras su retorno a tierras alicantinas, imbuído por las ideas místicas, erigirá una zāwiya (pequeño oratorio, lugar de piedad) de tendencia šădi $i గ$. Con el tiempo el oratorio pasará a ser la sede de una poderosa tarīqa o cofradía mística y Abū Ahmad Ibn Síd Bono el cabeza (šayj) de los sufíes contemporáneos. Ejerció de lector coránico en Valencia, (30) y allí lbn Al-Abbār le conoció personalmente con motivo de su asistencia en esta ciudad a una celebración religiosa islámica, en la noche de mitad del mes de šacbān del año 611/10 de diciembre 1214 (fiesta musulmana de Laylat al-barā'a).

Muere mediado el mes de $\underline{d} u-l-q a^{c} d a$ de 624 (27 octubre 1227) "pasados los ochenta» años, en la propiedad familiar de Zanita, sin dejar des- 
cendencia de varón. Fue enterrado en la mezquita de Adzeneta y a su funeral acudió "muchísima gente de todas las partes".(31) A esta tumba seguirán acudiendo muchos musulmanes hasta el s. XVI en busca de su beneficiosa baraka. M`. Jesús Rubiera y Míkel de Epalza han localizado los restos del mausoleo de esta familia de místicos; en base a los datos proporcionados por las fuentes árabes y a su identificación toponímica, ha sido posible reconocer la tumba de este santo musulmán en unos restos de muros hallados en la partida de Adzeneta (la qaryat Zanīta de las fuentes árabes), en la población de Benifato, sita en el Valle de Guadalest.(32)

6. Cronológicamente el siguiente miembro de la saga citado es su hijo, Gālib Ibn Hasan Ibn Ahmad Ibn Yahyà Ibn ST̃d Bono/a Al-JuzāT, Abū Tammām. Hijo de Hasan $\left(n^{\circ} .4\right)$ y sobrino de Yahyà $\left(n^{\circ} .3\right)$, vivió la mayor parte de su vida en tierras alicantinas. En este período en que la familia vivió en el Šarq Al-Andalus se inicia en las lecturas coránicas y en las prácticas místicas con su tío Yahyà lbn Sid Bono, llegando a sobresalir por sus notables cualidades, sus carismas y por su baraka. Fue muqri $\bar{r}^{\prime}$, de cadí, y un maestro reconocido.

A Abū Tammām Gālib Ibn Hasan Ibn ST̃d Bono/a le tocará vivir la salida de la familia del Valle de Guadalest y el exilio, primeramente trasladando su residencia a Elche, para luego saltar definitivamente a Granada. En esta ciudad desempeñará la función de cadí (cargo que con posterioridad ejercerán otros miembros de la familia), muriendo en ella en el $651 / 1253 \cdot 4 .(33)$

A partir de este momento, las noticias que tenemos de la familia de los Sid Bono se desdoblan. Por un lado conocemos la instalación de la familia y su relevancia en Granada, su nueva ciudad de adopción, mientras, que, por otro, también sabemos que su mausoleo siguió desempeñando un papel muy importante en la vida religiosa de los mudéjares del Levante peninsular.

\subsubsection{En Granada, los Banū STd Bona.}

En Granada los Sid Bono levantinos se instalan en el arrabal del Albaicín (Al-Bayyāzīn). Este barrio granadino había ido poblándose progresivamente con el contingente humano de musulmanes emigrados en su mayoría desde el Šarq Al-Andalus; entre ellos estuvieron los Síd Bono. Allí situaron su sede y allí también construyeron una zãwiya, como oratorio de la cofradía mística; en este barrio se fundamentará su poder y prosperidad.(34) Durante su estancia granadina la familia Síd Bono tuvo una gran relevancia, especialmente debido a la cofradía mística de la que eran cabezas y a su desempeño de la judicatura.

7. Gālib Ibn Hasan Ibn Gālib Ibn Hasan Ibn Ạmmad Ibn Yạ̣yà Ibn Síd 
Bono/a Al-Juzā̄T, Abū Tammām. Era nieto del anterior $\left(n^{\circ}, 6\right)$ por línea paterna y de Hasan $\left(n^{\circ}\right.$. 4) por la materna. Nació en dū $1-q a^{c} d a$ del 653/2 a 31 diciembre 1255 y vivió en el Albaicín, muriendo ctogenario en Granada el 10 de šawwäl 733/24 junio 1333.

Destacó por sus virtudes y por haberse dedicado por completo a la práctica del ascetismo, motivo por el que Ibn Al-Jatib le elogia abiertamente, aunque con algunas reticencias sobre su ortodoxia mística. Tras la muerte del antes citado fue nombrado šayj de la tarīqa.(35)

8. De Ahmad Ibn 'AlT Ibn Síd Bona Al-JuzāT', Abū Yacfar sólo se conocen sus maestros, que fue especialista en historia y en genealogías $Y$ que murió en 754/1353.4.

9. $\hat{Y} a^{c} f a r$ Ibn Ahmad Ibn ${ }^{c} A \sqrt{1}$ Ibn Síd Bona Al-JuzāT, Abū Ahmad según Ibn Ál-Jatib nació en en Granada 690/1291 y era hijo del anterior. No se tiene otra noticia de él hasta el 734/1333.4 en que es nombrado cabeza de la cofradía mística. Ibn Al-Jatib le elogia largamente. Consiguió notables adhesiones $y$, a pesar de llegar joven al cargo, fue uno de los principales personajes entre los sufíes granadinos, tanto por su influencia religiosa, como por el potencial económico centalizado en su cofradía. Murió el 29 de ramadān de 765 (30 de junio 1364).(36) En ciertas ocasiones, según Ibn Al-Jatīb, el sultán llamaba a la cofradía a su palacio de la Alhambra para participar de este ambiente sobrenatural y recibir sus beneficiosas barakāt.(37)

10. Muhammad Ibn Sĩd Bona es el último miembro de la cofradía citado por los autores árabes. Fue uno de los ulemas de Granada y se dedicó a continuar la labor mística y de cadiazgo de sus antepasados. Se sabe que aún vivía en $888 / 1483 \cdot 4 .(38)$

Es la última cita de las fuentes árabes que alude a un miembro de los los Banū Síd Bono/a, familia de cadíes(39) y místicos que tuvo una relevancia importantísima en el Albaicín, por la abundancia de seguidores, la riqueza de su cofradía, y porque eran requeridos por los sultanes granadinos a palacio (muestra de la gran fe en su baraka y bondad en ellos depositada).

\subsubsection{El origen del nombre y de la familia de los Banū Síd Bono.}

Hasta ahora se pensaba que el nombre familiar de Sid "Bona", que adopta la familia a partir de su estancia granadina se correspondería con un origen en Bona, ciudad argelina hoy denominada Annaba; Bosch Vilá y $M^{a}$. I. Calero recogen las interpretaciones de An-Nubāhī e Ibn Al-Jatỉb, que los hacen originarios de la ciudad argelina.(40) Por el contrario, otros autores árabes como Ibn Al-Abbār, Ibn Az-Zubayr y Al-Maqqañ̄, y otros investigadores modernos, utilizaron el apelativo de Sid "Bono". 
La duplicidad de mención en las fuentes árabes entre Bono y Bona para el nombre familiar puede tener su explicación. En la lápida de Benimaclet aparece el nombre de Bono; igualmente el valenciano Ibn Al- ${ }^{c} \mathrm{Abbār}$, que conoció personalmente a $\mathrm{Ya}^{c} \mathrm{far}$ Ibn ${ }^{\mathrm{C}} \mathrm{Abd}$ Allāh lbn Muhammad Ibn Sid Būnuh Al-JuzāT, deja bien explícita la escritura de su nombre. Estos testimonios del período levantino de la familia dejan, a nuestro parecer, bien claro que el nombre familiar era el de "Bono". El problema onomástico surge por el hecho de que en el período granadino de la saga, a esta misma familia se le denomina como Banū Sid Bona. El cambio en el nombre familiar posiblemente sea consecuencia de la emigración a Granada. En el medio social granadino, aunque fuera conocida la rábita en la que orara el santo fundador de la cofradía mística de los Sid Bono al regreso de su peregrinación a La Meca, eran unos emigrantes venidos al Albaicín, como tantos otros levantinos; en este medio granadino había otros Bono conocidos: se trata de la familia del alfaquí Ibn Bono, de origen malagueño.(41)

No es extraño, por tanto, que se decidieran por un cambio de nombre. El proceso de la mutación onomástica fue sencillo, y consistió en añadirle dos puntos diacríticos a la $h \bar{a}{ }^{\prime}$ final de su nombre, convirtiéndola en tā" marbūta, con lo que de "Bono" pasó a ser "Bona". La finalidad sería la de evitar la confusión con los Banū Bono malagueños y la de darse un prestigio como procedentes de la ciudad homónima magrebí.

Desentrañada la duplicidad onomástica entre Bono/a queda por explicar el origen de la familia, pero antes de pasar a este punto es importante aclarar el sentido que tiene el epíteto árabe de Síd. Es un título poco corriente en la onomástica andalusí, que tuvieron un reducido número de personajes notables; desde el conocido gramático y filósofo Abū Muhammad 'Abd Allāh Ibn Muhammad Ibn As-Síd Al-Batalyawsī (442$521 / 1050 \cdot 1-1127$ ), que, nacido en Badajoz, residió en diversos lugares del Šarq Al-Andalus y murió en Valencia, (42) hasta el famoso Cid Campeador, Rodrigo Díaz. Los casos aludidos tienen en común la coincidecia en Valencia a partir de mediados del s. XI.

El epíteto de Síd -como ha expresado Míkel de Epalza- es un título honorífico de carácter militar no muy corriente. No sería una derivación del árabe sayyid, señor, como se ha dicho comúnmente; no es un título de respeto (raro en árabe en el tratamiento por escrito), sino un epíteto de origen militar que en árabe dialectal Míkel de Epalza interpreta como el León, aplicado a Rodrigo Díaz.(43)

El nombre familiar de los Síd Bono está documentado en el año 364/ 974.5, cuando el cronista árabe Ibn Hayyān recoge del Ta ${ }^{c}$ rij de Ar-Rāzī 
la noticia de la entrega de diplomas de gobierno a los jefes militares de la frontera toledana: entre los más conocidos se cita en primer lugar a «Muhammad e "Tsà, hijos de Surūr Ibn Bono",(44) El hecho de que también aparezca el nombre en la documentación mozárabe anterior a la conquista de Toledo en el 1085, induce a pensar que algún militar de la familia de los Banū Sid Bono fuera de origen toledano y se trasladara desde Toledo a Valencia en algún momento posterior a la fitna que acabó con el califato, posiblemente aprovechando la alianza entre los Banū Dî-n-Nūn de Toledo $y$ 'Abd Al-cAziz de Valencia (consecuencia del matrimonio de la hija del primero con el hijo del valenciano). Ya bastante antes de la incorporación militar de Valencia y Xàtiva al reino toledano había una notable relación militar entre ambas; como consecuencia de ella acudirían desde Toledo a Valencia los Bono toledanos(45) y en esta urbe valenciana se les otorgó el epíteto de Sid al nombre originario, como ocurrió en los otros dos casos citados.

En el siglo $V / X I$ están documentados en Toledo y Valencia, antes de las noticias que aluden a su residencia en el Valle de Guadalest. La estela funeraria hallada en Benimaclet, datada en 453/1061, alude a esta primera residencia de la familia Sid Bono en Valencia. Por su estatus, y como era habitual entre los musulmanes nobles o ricos, seguro que tuvieron numerosas fincas rústicas y propiedades urbanas. El topónimo Real de Bono,(46) a la salida de Cocentaina en dirección a Muro de l'Alcoià, posiblemente no haga sino confirmar la existencia de esas propiedades inmediatas a la capitalidad del distrito administrativo, en la cual residirían. Entre las fincas rústicas que poseyeron, estaría la de Zaníta, en el Vall de Guadalest.

A ella se trasladarán en una fecha indeterminada; seguramente buscando refugio ante los hechos violentos y la inestabilidad que supuso la venida de Rodrigo Diaz, el otro Cid, el Campeador, a Valencia y la toma de ésta por sus huestes. Entre los muchos musulmanes que huyeron de la urbe estarían los Banū Síd Bono.(47) A partir del abandono de Valencia es cuando se trasladan a la alquería de Adzeneta, en el Valle de Guadalest. Allí comienza un nuevo período en la vida de la familia que les hará famosos por ser los dirigentes de una importante cofradía mística.

3.2.4. El período mudéjar valenciano de los Banū STd Bono.

En el caso de esta familia, por fortuna, las fuentes cristianas posteriores a la conquista catalano-aragonesa del Šarq Al-Andalus vienen a completar los datos aportados por las fuentes árabes. En el corpus documental publicado por $\mathrm{M}^{\mathrm{a}}$. Teresa Ferrer i Mallol sobre los mudéjares alicantinos (48) se recogen cuatro documentos que hablan de la pervivencia 
en el Vall de Guadalest del mausoleo de un santo musulmán al que acudían muchos musulmanes en peregrinación.

Según esta documentación cristiana en la mezquita de Adzeneta se conservaba la tumba de un santo musulmán de enorme fama, debido a lo cual venían peregrinos no sólo del reino de Valencia, sino de Granada y hasta de "Berbería". Indudablemente, por lo ya apuntado, esta mezquitamausoleo de Adzeneta se corresponde con las diversas noticias de las fuentes árabes que ubican en la alquería de Zanita el solar de los Banū Sid Bono.

Los dos primeros documentos hablan del intento real de poner un impuesto a todos los musulmanes que acudieran al mausoleo de Guadalest a rezar en la tumba del santo. No se menciona expresamente el lugar concreto de Adzeneta, sino el de Guadalest, el municipio al cual pertenecía éste lugar. Una parte de este impuesto debía destinarse a la reparación de las murallas y la fortaleza de este importante castillo. El segundo documento revoca este impuesto, ante la queja de las aljamas del reino por el mismo. No parece que hasta entonces hubiera restricción alguna a la peregrinación de musulmanes a Adzeneta.

Pero a partir del tercero de los documentos, de 1379, se deja traslucir la preocupación que suscitaba esta peregrinación en la corte catalanoaragonesa. La multitud islámica que se congregaba era grande y heterogénea, proveniente de la Península y en buen número del Mágreb, muchos acudian armados y se temía que por esta circunstancia se produjesen incidentes peligrosos. A partir de este momento, los documentos indican una progresiva restricción del acceso de los musulmanes al mausoleo de Vall de Guadalest.(49)

Pero, a pesar de todos los impedimentos que los oficiales reales quisieron imponer a las peregrinaciones a la tumba de los Sid Bono, éstas seguian produciéndose. En contrapartida, las restricciones de peregrinar al mausoleo de los Sid Bono se van haciendo mayores cuanto mayor es el contingente de musulmanes de toda la Península y del Mágreb que acuden a Adzeneta. No hay más documentos contemporáneos que permitan seguir los acontecimientos, pero no se debió acabar definitivamente con esta costumbre anual de los musulmanes valencianos (aunque en época del rey Martín pasará a ser una manifestación semiclandestina). Consecuencia de los desórdenes de la revuelta de las Germanías, o bien por orden de las autoridades civiles, la mezquita de Adzeneta fue destruida. A pesar de ello, continuaron los moriscos acudiendo ocultamente.

No mucho después la mezquita-mausoleo será reconstruida, gracias a la colaboración del señor de los valles de Seta y Guadalest, el Almirante de 
Aragón Sanç (o Sancho) de Cardona. Como resultado de esta condescendencia hacia los moriscos será preso y juzgado por la Inquisición. Sanç de Cardona fue condenado en 1540, aunque por su edad avanzada, linaje y posición la pena impuesta fue más que suave.(50) Sanç de Cardona fue encarcelado en 1569 y la sentencia de reclusión en un monasterio le fue comunicada en 1570. Con ello, el culto en la mezquita-mausoleo de Adzeneta, afectado por una segunda destrucción ordenada por Felipe II, debió recibir el golpe definitivo.

Hay que resaltar el arraigo, importancia y aprecio entre los musulmanes andalusíes de la baraka del mausoleo de la familia de los Sid Bono; ésto contribuirá a la continuación de las peregrinaciones al mismo, aún después de la conquista cristiana, del abandono de los Banû Sîd Bono de Adzeneta y de su emigración a Granada, de las medidas restrictivas del período mudéjar $y$, finalmente de la prohibición de acudir al mismo tras su forzada conversión al cristianismo. En segundo lugar, hay que señalar la fama de este mausoleo, que atraerá a musulmanes de toda la corona Catalanoaragonesa, de Granada, e incluso del Mágreb. Finalmente es notable la condescendencia con sus súbditos moriscos del Almirante de Aragón, tolerancia no muy común entre los señores contemporáneos.

3.2.5. La conquista cristiana de Granada y la familia de los Banū Síd Bono/a.

A pesar de la importancia de los Síd Bono como dirigentes de la comunidad mística de Guadalest y Granada y de su relevancia como familia de cadíes, no hay noticias de que, con la conquista de Granada, emigraran al Mágreb, como hicieron un enorme número de granadinos, y como sería de esperar de unos musulmanes tan fervientes como afirman las fuentes árabes que eran, aunque, quizás, algunos miembros de la familia así lo hicieron.

Al contrario, las noticias afirma que algunos miembros de la familia se quedaron. Un documento de tiempos de Isabel I recoge la donación por parte de los Reyes Católicos el 15 de marzo de 1500 "a Pero López, que se solia llamar el alfaqui Çid Bona, ocho mill maravedies (...) de los quales el rey nuestro señor les hizo merçed", como premio por su conversión al cristianismo. La identificación con un miembro descendiente de los Sîd Bona granadinos no presenta problemas onomásticos, añadiendose el dato de su anterior profesión como alfaquí.

Es más difícil de asegurar una plena identificación onomástica en el caso de otras dos donaciones como premio por sendas conversiones al cristianismo: "4.000 m. (aravedies) de por vida a Fernando Zahabona, antiguo faquí. 1 diciembre 1500 y la de $10.000 \mathrm{~m}$.(aravedies) de por 
vida a Pedro Lopez de Zahadbona, regidor de Granada. 11 de octubre $1501 »$. Es interesante la referencia documental sobre los premios económicos entregados a cambio de la conversión de los alfaquíes y los altos cargos, como el caso del regidor de Granada.(51)

Estos y otros datos muestran el cambio de religión de algunos miembros de los Sid Bono/a. Las referencias citadas hablan del claro deseo de conservar los diversos estatutos de privilegio que poseían antes de la conquista de Granada, no dudando para ello en convertirse al cristianismo. Toman además una serie de apellidos bastante corrientes, que evitarían su identificación como antiguos musulmanes.

Este el el fin de las noticias que poseemos de esta importantíusima familia de musulmanes de origen toledano, que emigraron a Valencia durante el período de las taifas, y que acabaron residiendo en la capital comarcal de la montaña alicantina, Cocentaina. En esta montaña tuvieron y explotaron la importante finca de Adzeneta, en la que estaba enterrado el santo de la familia. Con la conquista cristiana todo se trastocó trágicamente. La familia siguió evolucionando en Granada, poderosa e influyente, mientras que en Adzeneta perduró hasta el siglo XV la veneración de los musulmanes que se quedaron en estas tierras por el mausoleo de los Sid Bono.

\subsection{Contestanos "de adopción".}

En último lugar hay que considerar los personajes cuyo origen no se sitúa en directa relación con Cocentaina, pero de los que se dice que durante un período de su vida estuvieron viviendo en ella. Cronológicamente el primero que refiere Ibn Al-Abbār es Abū Bakr ${ }^{C} A$ tíq Ibn Ahmad Ibn Muhammad Ibn Jalid Al-Majzūmī, Ibn Al-Jasm, de origen min ah/ Valencia, de quien aporta una larga lista de maestros, y dice que fue lingüista, alfaquí, ulema y tradicionista. Muere en Cocentaina "sita hacia Denia" (bi-Qustantāniya min ŷihat Dāniya) en ŷumādà / del 548/25 julio-23 agosto 1153, aunque fue enterrado en Valencia.(52)

El segundo personaje lleva por nombre Abū l-Hasān Muhammad Ibn

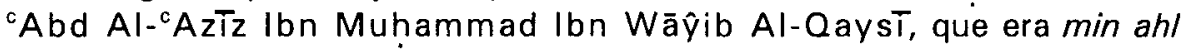
Valencia, y ejerció el cadiazgo en Qustantāniya y en otros lugares próximos en el Levante (wa-gayri-hā min al-y̌ihāt aš-šarqīya). Murió en Bairén en 553/1158.9.(53)

El último es Abū Bakr Muhammad Ibn Ibrāhīm Ibn Ahmad Ibn Jalaf Ibn Ŷamäat Ibn Mahdí Al-Bakrī, que era min ahl, de familia de Denia. Fue cadí en su tierra y experto en ahkām, experto en contratos ( ${ }^{c} a q d$ aššsurūt) y buen calígrafo, entre otras virtudes. Murió en Murcia en $581 / 1185 \cdot 6$, y allí se le hizo la oración fúnebre; pero fue conducido a 
Qustantāniya, siendo alli enterrado con sus antepasados.(54) En este último caso, aunque no se puede hablar que fuera originario de la propia ciudad, podemos hablar de una familia, la de los Banū Ŷamāca, que sí lo era.

De este modo acabamos el repaso a las biografías de contestanos por algún motivo célebres que Ibn Al-Abbār u otros historiadores mencionaron. Hasta aquí los datos singulares y humanos. Seguidamente analizaremos otros aspectos históricos y terminológicos que cabe deducir de las anteriores noticias.

\section{COCENTAINA COMO CAPITAL COMARCAL EN EL SIGLO XIII.}

Una vez apuntados los datos biográficos de los contestanos que conocemos gracias a las referencias de las fuentes escritas árabes, vamos a centrarnos en el segundo grupo de noticias que nos transmiten los geógrafos e historiadores árabes. Esta segunda categoría de informaciones, deducible de las anteriores referencias, nos aporta una inapreciable serie de datos: son los que hablan de Cocentaina como ente poblacional integrado en una división administrativa en la que desempeña una capitalidad comarcal.

\subsection{La fijación de un topónimo pre-árabe.}

Los autores árabes mencionados tuvieron diferentes criterios para la fijación por escrito de un topónimo claramente pre-árabe (y prelatino) como es "Cocentaina". En la siguiente relación se recogen las variantes:

- Al- 'Ud rĩi: Kürat Balansiya: ... yuz Qustāniya ...(55)

- Yāqūt Al-Hamawĩ: hisn Qusantāna ... min camal Denia.(56)

- Ibn Al-Ab bār: en la Tákmilat li-Kitāb as-s7la cita el topónimo:

- bajo la forma Qustantāniya camal Dāniya (ó min yihat Dāniya) (9 veces),(57)

- hay una alternancia con Qusantāniya camal Dãniya len 1 caso), (58)

- y en una ocasión se conserva escrito min ahl Qusantäna camal Dãniya.(59)

- Ibn Al-Abbār: en Al-Mu $u^{c} \hat{y} a m$ fi ashab al-qādà al-imām $A b T^{c} A \pi$ As-Sadafi lo cita una única vez: $\ddot{m i n}$ ahl Qusantäniya, 'amal de Dénia. (60)

- An-Nubāhĩ: no menciona este enclave (fa-istawtana min-ha Wãdi Laštat, min camal Dāniya ...),(61) pero toma la noticia de Ibn AzZubayr, quien sí afirma: qaryat Zanītat min Wãdi Laštat šarqĩ Al-Andalus, min camal Qusantāniya(62) 
- Ibn Al-Jatīb: en la biografía de Abū Tamãm lbn ST̃d Bono indica su origen familiar en: qaryat Zanitat min Wãdi Laštat šarqĩ AlAndalus, min camal Qusantãniya(63)

- Al-Maqqarī: min ahl Qustatāniya(64)

Hay dos modos de transmitir el nombre: bien como un topónimo local que forma parte de una división administrativa (ŷz $\left.z^{c},{ }^{c} a m a h\right)$, o bien para calificar a alguien como perteneciente a sus pobladores: $\min$ ahl, traducible como de familia de ..., de la gente de ... Hay que resaltar que de las numerosas noticias que hablan de Cocentaina ninguna califica el topónimo como madina, qarya, hisn, etc. como es corriente hasta la época almohade. La razón es que la nueva división administrativa impuesta por ellos cambió radicalmente la concepción, categoría y denominación de los espacios.

La nota común es la metátesis y/u omisión de alguna de las letras de la secuencia $>$ st_nt_n $<0>$ s_n_t_n $<$, con tendencia a acortar un nombre tan largo y extraño a la lengua árabe. El más antiguo de los

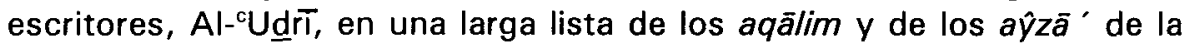
Kürat Balansiya, cita casi en último lugar al de Qus[an]tāniya. El otro autor que conocía bien el Šarq Al-Andalus fue Ibn Al-Abbār (èl último que los vió en tierrras levantinas): éste lo escribe mayoritariamente como Qustantāniya (9 veces) o como Qusantāniya (2 veces). Por conocimiento y cercanía geográfica son los dos autores más fiables. El resto de escritores posteriores parece que han tomado el dato sobre su origen de Ibn AlAbbār.

Aunque diferentes, entre Qustāniya y Qustantāniya únicamente hay una reduplicación del grupo fónico $>\tan <$. Si tomamos como étimo preárabe el de Contestania, las diversas grafías árabes buscan aproximarse a lo que debió ser la pronunciación de un topónimo no fijado por escrito, como otros de idéntico origen latino, o pre-árabe. De la inseguridad fonética del topónimo habla la circunstancia de que los escribanos catalanes tampoco supieron fijar el topónimo adecuadamente tras la conquista. $(65)$

4.2. La terminología administrativa del Šarq Al-Andalus. Cocentaina como capital comarcal.

Por su ubicación geográfica en el Šarq Al-Andalus Cocentaina perteneció en el período del califato (s. IV/X) a la provincia o Küra de Valencia, demarcación provincial que englobaba los actuales territorios de Valencia y norte e interior de Alicante (según se deduce, por ejemplo, de la la referida noticia de $\left.A{ }^{-}{ }^{C} U \underline{d} \tilde{i}\right)$. Durante el período de las taifas (s. $\left.V / X I\right)$, estuvo englobada dentro de la Taifa de Denia; recordemos que los Banū 
Jamīs mencionados acudieron a estudiar a la metrópoli taifal de Denia.

Poco más se puede añadir respecto a estos primeros siglos de la historia musulmana de Cocentaina. Únicamente que, según parecen confirmar los restos arqueológicos, la ciudad islámica estaba bajo el solar de la actual Cocentaina, de lo que se deduce la perduración en el hábitat urbano.

Ibn Al-Abbār (595-658/1199-1260), valenciano y buen conocedor del Levante de la Península, dejó un importante repertorio antológico de biografías de valencianos o gentes que tuvieron relación con Valencia. De estas biografías diversas Míkel de Epalza ha extraído los lugares de donde eran originarios los personajes biografiados, y ha puesto en relación jerárquica estos lugares entre sí, deduciendo lo que sería el mapa administrativo del Šarq Al-Andalus anterior a la conquista cristiana.(66) Ibn AlAbbār deja reflejada en su obra la estructura de la última ordenación administrativa, la de época almohade, el último régimen político que gobernó sobre las regiones del Šarq Al-Andalus. Este autor menciona los lugares y los califica a partir de su conocimiento directo, con la finalidad de situar claramente a los personajes biografiados y sus actividades. Su obra fue acabada en Túnez. Para precisar aún más la situación de unos lugares desconocidos (pensando en sus lectores magrebíes) la rehará en su nueva residencia. Como consecuencia, sus descripciones y ubicaciones geográficas ganarán en exactitud.

De la terminología empleada por este autor Míkel de Epalza ha deducido la existencia de una clara estratificación administrativa de los espacios, introducida por los almohades tras su reforma administrativo-militar. Hay una clara categoría de los enclaves poblacionales, siempre en relación con las ciudades (no hemos de olvidar que la sociedad islámica es esencialmente urbana): en primer lugar estarian las metrópolis o capitales; dependientes de ellas estarían una serie de $a^{c} m a \bar{l}$, y finalmente, cada ${ }^{c} a m a l$ englobaría a una serie de núcleos inferiores de población: las alquerías y los lugares.

El camal, profusamente citado con anterioridad, sería la denominación aplicada a una ciudad con capitalidad jurisdiccional, y por extensión, al territorio de ella dependiente. Según Ibn Al-Abbār, la división almohade del siglo $\mathrm{VI} / \mathrm{XII}$ está basada en el camal gubernamental, y centrada en sus capitalidades comarcales. También el camal tiene un sentido militar, pues es la sede donde reside el ${ }^{c} a \tilde{m}$ il (gobernador militar). Es una consecuencia más de la reforma administrativo-militar almohade, cuya finalidad fue reforzar militarmente las regiones fronterizas para frenar en lo posible el avance de los cristianos. Igualmente es la sede de la recaudación fiscal de su comarca. 
Por encima de esta categoría de los $a^{c} m \bar{a}$ l (plural de ${ }^{c} a m a /$ se encuentran las ciudades capitalinas, las metrópolis; de cada una de ellas depende en función directa una serie de $a^{c} m \bar{a} l$. La ubicación de los lugares es expresada de uno de los siguientes modos: es un «/ugar $X$, del ${ }^{\circ}$ amal $Y_{\Perp}$, o es un "lugar $X$, de los $a^{c} m a ̄ l ~ d e ~ Y »$. Las alquerías son núcleos de población menores y son unidades básicas de explotación de las tierras; su tamaño variaba de ser una simple agrupación de pocas casas a ser pequeños pueblos. Más indeterminados son los diferentes enclaves que se califican como mawādr o lugares (singular mawdr). Estas dos denominaciones se aplican a enclaves menores de población dependientes de la capital comarcal.

Otro término utilizado por Ibn Al-Abbār es el de yiha (plural yihāt), con el significado de dirección a, alrededores de, hacia, como localización geográfica relativa que no refleja ninguna circunscripción administrativa. Así Ibn Al-Abbār afirma que Ibn Jamīs fue "cadí en Cocentaina y en otros ŷihāt levantinos", $y$ en otro lugar sitúa Cocentaina en relación a Xàtiva al afirmar que está en el ŷihāt de Xàtiva, o sea, hacia los alrededores de esta ciudad. Importante dato que pone en relación a Cocentaina, ya no con Denia (su metrópoli), sino geográficamente con Xàtiva, la otra importante capital del levante (con la que estaba bien comunicada a través de las montañas y con la que debió mantener siempre una muy importante relación económica).

El término yuz ' (recogido en la noticia de Al- ${ }^{\circ} U \underline{d}$ rī de que Cocentaina era en el siglo IVIX un ŷu ' dependiente de la Küra de Valencia) tiene por significado parte, distrito, partida menor. Pero hay que advertir que este término se encuadra dentro de otra división administrativa dos siglos anterior a là que refleja Ibn Al-Abbār.

Una vez definidos los términos empleados en esta división administrativa de época almohade, vamos a centrarnos en el análisis que hace $M$. de Epalza de las poblaciones dependientes de la metrópoli de Denia. De ella dependían según Ibn Al-Abbär tres $a^{c} m a \bar{l}:$ Cocentaina, Bairén y Batruša (que identifica con Pedrosa, cerca de Xàtiva). Entre las alquerías y lugares que cita como dependientes de Denia están la alquería de Ondara, el ribāt de Denia, la alquería de Pego, y la Luša (identificada como Llosa de Camatxo). Dentro del ${ }^{c} a m a l$ de Bairén cita dos alquerías: Palma de Gandía y Beniopa.(67)

Como se aprecia, no se trata de un panorama cerrado, pues hay lagunas geográficas que no sabemos a qué ente administrativo pertenecían. A pesar de ello, esta identificación supone un gran avance respecto a la total ausencia de noticias al respecto que teníamos antes de este 
estudio de M. de Epalza.

Tras la definición de los términos empleados por los árabes para designar las divisiones administrativas del $\mathrm{s}$. $\mathrm{VI} / \mathrm{XII}$ se pueden comprender mejor las referencias que se han recogido anteriormente, como la de Abū Tammām, el último de los Síd Bono valencianos, quien según lbn AlJatib era "perteneciente al distrito de ('amal) de Cocentaina (Qusantāniya), donde poseyó abundantes rentas (āmwālā)...». Con ello, lbn AlJatib nos habla de una rica familia, que residiría en la capital comarcal, Cocentaina. por más que la mezquita-mausoleo estuviera en una de sus fincas rústicas de la montaña, Adzeneta, en el Valle de Guadalest, y que poseyeran otros bienes rústicos y urbanos en la comarca. El topónimo Real de Bono (situado a la salida de Cocentaina en dirección a Muro de l'Alcoià) posiblemente no haga sino confirmar la existencia de esas propiedades inmediatas a la capitalidad del distrito administrativo, en la cual residirían.

\section{LA IMPORTANCIA GEOPOLÍTICA DE COCENTAINA.}

Cocentaina fue la ciudad que desempeñó en los siglos VI/XII y VII/XIII la capitalidad administrativa de una poco conocida comarca, que englobaría la montañas de los valles de Cocentaina-Alcoy, región del Comtat y Vall de Guadalest, grosso modo. Pero hay que añadir un dato esencial que aunque no lo refieran las fuentes árabes, se deduce de su ubicación geopolítica. La importancia del enclave urbano de Cocentaina se debía a su situación estratégica en el mapa viario del levante peninsular $y$ a las poblaciones importantes con las que esta red viaria le comunicaba. (68)

Esta situación estratégica le venía conferida por estar en un cruce entre dos importantes vías de la época islámica. Como lo indicamos en el esquema gráfico adjunto.

Por un lado se encuentra la Vía Augusta (resaltada en negro en el esquema), importante eje de todo el levante peninsular en su trazado que desciende paralelo a toda la costa mediterránea hasta Valencia, entrando luego hacia el interior, para proseguir por Alcira, Xàtiva, Ontinyent, Bocairent, Biar y seguir descendiendo por el Valle del Vinalopó.(69) Por este importante eje discurriría la mayor parte de la vida económica y militar del levante desde la época de los romanos. Desde la misma se accedía al interior montañoso alicantino, a partir de Xátiva, atravesando el Vall d'Albaida y Benicadell hasta Cocentaina, centro y capital comarcal. A su vez, otro camino transversal uniria la Vía Augusta, a partir de Biar, atravesando la Foia de Castalla, por Alcoy, con esta región de la montaña. 


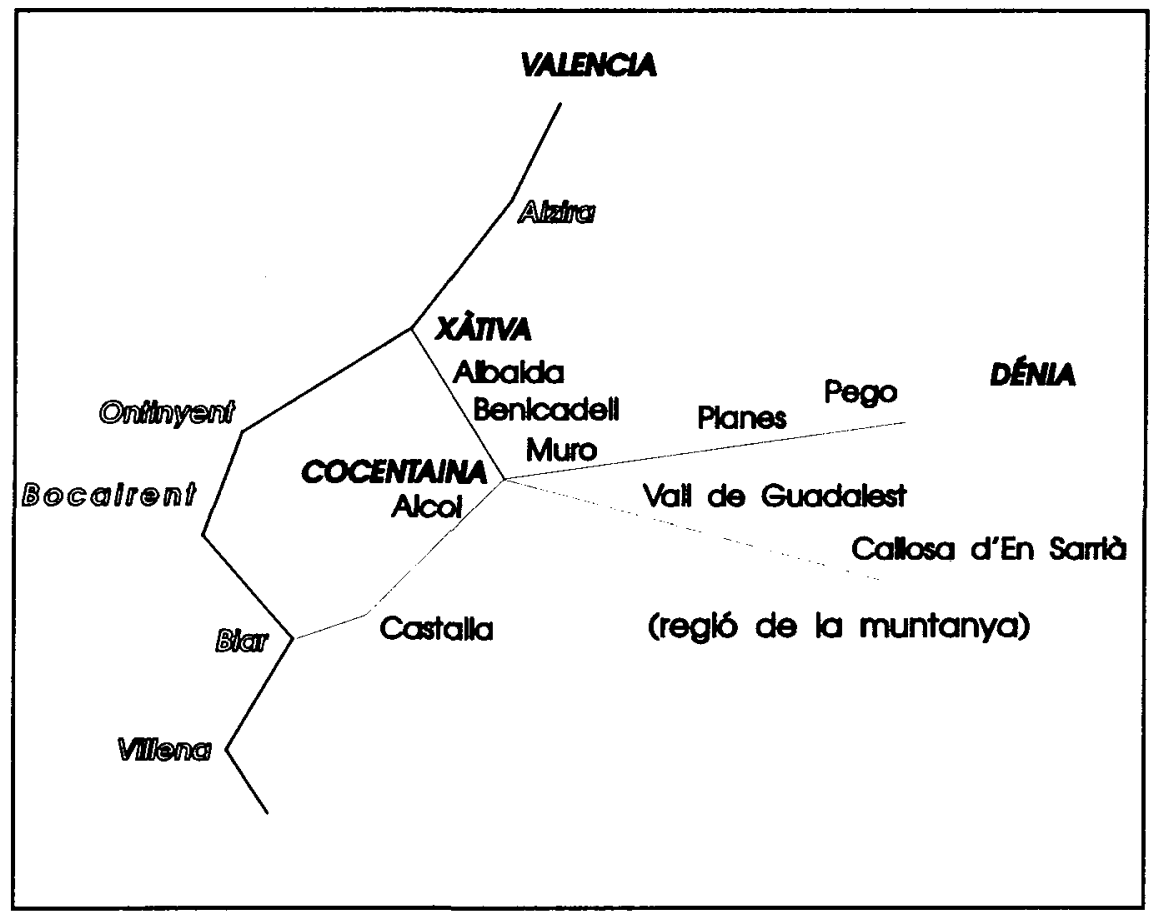

No hay que olvidar que el topónimo Alcoy, -como ha mostrado $M^{a}$. Jesús Rubiera- no es sino un nombre latino: el coll, o sea, el alto, lugar elevado desde el que se observa, se domina, una zona de paso que está a su pie. (70) Es un topónimo vial de origen latino que nos ha perdurado a través de la fonética del árabe.

A su vez, desde Cocentaina se podía seguir camino hacia la metrópoli deniense a través de Muro de l'Alcoià, de Planes y Pego, o continuar en dirección a la costa, más al sur, atravesando la montaña por el Vall de Guadalest y Callosa d'En Sarrià.

Como se ve, Cocentaina se encuentra ubicada en un esencial nudo de caminos. De este modo se entiende tanto la capitalidad comarcal, de la que nos hablan los historiadores andalusíes, como sus privilegiadas relaciones con Xàtiva y Denia, que reiteran las citadas fuentes árabes. Era un importante enclave militar desde el que se dominaba la circulación de personas y mercancías $y$ desde el que se controlaba la estabilidad de toda la comarca. A su vez, su importancia como centro económico, consecuencia de ser un nudo vial, le conferiría un importante papel como 
centro de comercio y distribución.

\section{EPÍLOGO.}

Tras el panorama expuesto no cabe sino concluir que, a pesar de las pocas noticias de época islámica que han perdurado, éstas nos permiten una aproximación bastante cercana a la Cocentaina árabe.

Como centro administrativo, judicial, económico y militar desempeñó un relevante papel desde el siglo IV/X (o desde antes), aunque no tengamos noticias escritas sino a partir del siglo $\mathrm{V} / \mathrm{XI}$. El avance de la conquistas cristianas por Cataluña, Aragón y centro del Šarq Al-Andalus propiciaron una gran afluencia de musulmanes emigrados hacia el sur desde el siglo $\mathrm{V} / \mathrm{XI}$, pero especialmente en los ss.VI/XII y VII/XIII. Esta es la razón del auge poblacional de las comarcas meridionales del levante y centro peninsular, y es la causa por la cual personajes de estas regiones citadas se multiplican desde entonces en los repertorios biográficos. El mismo proceso nos refiere Ibn Al-Jatib: una vez conquistadas las tierras šarqies, sus habitantes se concentrarán en el barrio del Albaicín, donde seguirán en vecindad y en donde contribuirán al esplendor de la taríqa de los Síd Bono (ya entonces Síd Bona).

Cocentaina, como centro comarcal tuvo una estrecha relación con su metrópoli, Denia, y con la otra capital del levante, Xàtiva, en virtud de sus buenas comunicaciones con ellas. Esta unión viaria explica tanto las privilegiadas relaciones intercomarcales, como algunos acontecimientos históricos o bélicos: la toma por el Cid del castillo de Benicadell fue una jugada de ajedrez que inmovilizó todo el comercio y las comunicaciones entre la Vía Augusta, la Foia de Castalla, l'Alcoià y las Marinas alicantinas, por un lado, y por el otro, le permitía ejercer una fuerte tenaza sobre la cercana Via Augusta entre Xàtiva y Ontinyent. De igual modo, esta red de caminos y comunicaciones también ayuda a comprender los itinerarios y movimientos a lo largo de la montaña alicantina de Al-Azraq y los musulmanes que le apoyaban; etc.

La referida relación vial no únicamente se manifestó en el terreno de lo económico, administrativo o militar, sino que también en el campo de la cultura. A Denia acudirán dos de sus ilustres hijos, los dos Banū Jamīs que conocemos, y allí se formarán, siendo luego importantes personajes de la judicatura. De igual modo, en esta capital seguramente tuvieron su residencia los ricos e influyentes miembros de la familia de los 5id Bono/a, saga de místicos de la que tenemos bastantes noticias desde el siglo $\mathrm{XI}$; su influencia perdurará a través de los siglos, tanto en su nuevo domicilio del 
barrio del Albaicín granadino, como en el que dejaron atrás, el de Adzeneta de Guadalest

\section{FUENTES ÁRABES CITADAS}

- Ibn Al-Abbār (Abū 'Abd Allāh Muhammad lbn 'Abd Allāh Ibn Abī Bakr Al-Qudā T Al-Andalusī, Ibn Al-Abbār 595-658/1199-1260): Kitāb at-Takmilat li-Kitäb as-sila, ed. ár. de Francisco CODERA Y ZAYDÍN: Bibliotheca Arabico-Hispana. Vols. V y VI. Complementum Libri Assilah (Dictionarium Biographicum) ab Aben Al-Abbar scriptum. Partem, quae superest, ad fidem codicis escurialensis arabice nunc primum edidit, indicibus additis, Madrid, 1887-1889, 2 vols. [Vol. I, 1887, 412 pp.; biografías 1-1185/ vol. II, 1889, XIV , 413-964 pp.; biografías 1186-2152J. Correcciones a la anterior ed. de F. CODERA, y ed. de una parte suplementaria, aparecida en un nuevo ms., por Maximiliano ALARCÓN; Ángel GONZÁLEZ PALENCIA: "Apéndice a la edición Codera de la "Tecmila" de Aben Al-Abbar", Miscelánea de Estudios y Textos Árabes, Madrid, 1915, pp. 147-690 [biografías 2153-2982]. Ed. ár. de nuevas biografías de un ms. de Argel por: Alfred BEL; M. BEN CHENEB: Kitāb at-Takmilat li-Kitāb as-S·ila = Takmila-t-essila d'Ibn el-Abbâr (Texte arabe d'après un manuscrit de Fès). Tome I. (Cómplétant les deux volumes édités par F. Codera), Argel, $1337 / 1919$ (1920), $466+22$ pp [652 biografías en total]. Nueva ed. ár. de 'A. AL-'ATTĀR AL-HUSAYNİ: At-Takmilat li-Kitāb as-Sila, El Cairo, 1955-1956/1375, 2 vols. [Vol. I, 1955/1375 H., 351 pp.; biografías 1-1292 / vol. II, 1956/1375 H., pp. 468-944; biogr. 1293-2188].

- Ibn Al-Abbār (Abū 'Abd Allāh Muhammad Ibn 'A Abd Allāh Ibn Ab̄̄ Bakr Al-Quḍā T Al-Andalusī, Ibn Al-Abbār 595-568/1199-1260): Al-Mucyam fí ashàb al-qādà al-imām $A b \bar{i}^{c} A / i$ As-Sadafi, ed. ár. de Francisco CODERA Y ZAYDÍN: Almôcham (Dictionarium ordine alphabetico) de discipulis Abu Ali Assadafi ab Aben Al-Abbar scriptum ad fidem codicis escurialensis arabice nnunc primum edidit, indicibus additis, Madrid, 1886, $368+\mathrm{XIX}$ pp. [315 biografías].

- Ibn Hayyān (Abū Marwān Hayyān Ibn Jalạf, Ibn Hayyān Al-Qurtubī, 377-469/987-1076): Kitāb ai-muqtabis fi ta 'rij riȳài Al-Andalus, y de ella, su sexta parte lo Muqtabis VI, que incluye los años 360-364/971-975 del califato de Al-Hakam II), en que se recoge una parte de la obra histórica de 'T̄sà Ibn Ahmád Ar-Rāzī, trad. esp. de Emilio GARCÍA GÓMEZ: El Califato de Córdoba en el "Muqtabis" de Ibn Hayyān: Anales Palatinos del

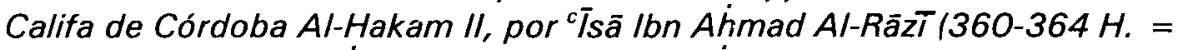
971-975 J. C.). Traducción de un ms. árabe de la Real Academia de la 
Historia, Madrid, 1967, $293 \mathrm{pp.}$

- Ibn Al-Jatīb (Lisān Ad-Dín Abū 'Abd Allāh Muhammad Ibn Al-Jatỉb 'Abd Allāh Ibn SaTîd Ibn 'Abd Allāh Ibn SaTd Ibn 'Ali Ibn Ahmad ÁsSalmānī Al-Garnātî, 713-776/1313-1375): Al-Ihātat fi ajbār Gaināta, ed.

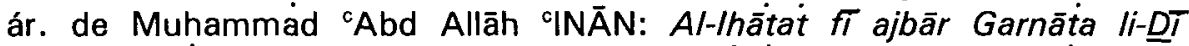
1-Wazāratayn Lisān Ad-Dīn Ibn Al-Jatỉb, El Cairo, 1973-1978, 4 voìs.

- Ibn Az-Zubayr (Abū Ŷacfar Ahmad Ibn Ibrāhīm Ibn Az-Zubayr, 627-708/ 1229-1308): Silat as-silat li-Ibri Baškuwāl, ed. ár. de É. LÉVI-PROVENÇAL, Rabat-París, 1938.

- Al-Maqqarī (Abū l-c'Abbās Ahmad Ibn Muhammad Al-Maqqar̄i At-Tilimsāni Al-Mālikī Al-Ašcarī, ca.' 998-1041/ca. 1590-1631): Nafh at-tỉb min gusn Al-Andalus ar-ratỉb wa dikr waziri-hā Lisān Ad-Dín ibn AlJatỉ, ed. ár. de lhsān 'ABBĀS, Beirut, 1968, 8 vols.

- Án-Nubāhī, Abū I-Hasan Ibn 'Abd Allāh Ibn Al-Hasan (m. ha. 798/ha. 1396): Kitāb al-marqábat al ${ }^{-}$ulyā ${ }^{\circ}$, reimpresión de la primera edición árabe de É. LÉVI-PROVENÇAL (EI Cairo, 1948) sin mención de editor: Ibn AlHasan Al-Nubāhī. Tã̄ij̄ qudāt Al-Andalus. Histoire des juges d'Andalousie intitulée Kitāb al-markabat al- ${ }^{c} u l y a ̄$, Beirut, s.a., X +246 pp.

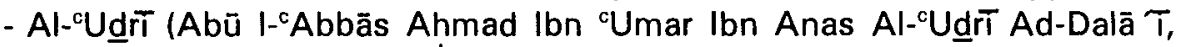
393-478/1002-3-1085.6): Kitäb tars $\bar{T}^{2}$ al-ajbār wa-tanwĩ al-ātār wa-/bustān $\mathrm{fi}_{\text {garā }}$ ib al-buldān wa-l-masālik ilà yamĩ al-mamālik, ed. ár. de la parte conservada de la obra por ${ }^{\mathrm{C}} \mathrm{Abd}$ Al- ${ }^{\mathrm{C}} \mathrm{Az \overline {Z }}$ AL-AHWĀNIT: Ahmad Ibn 'Umar Ibn Anas Al- ${ }^{c} U \underline{d} r \bar{r}$. Fragmentos geográfico-históricos de Al-Masālik ilà ğamĩ al-mamālik, Madrid, 1965, 228 pp.

- Yāqūt Al-Hamawī (Abū 'Abd Allāh Yãqūt lbn 'Abd Alläh Al-Hamawĩ AlBagdāđT̃ Ar-Rūmī, ca. 575-626/ca. 1179-80-1229): Mưcyam al-buldān, ed. ár. de Ahmad AMĪN AL-JĀNAŶTi, Ahmad IBN AL-AMĪN AŠ-ŠINOĪTT̄ y otros, El Cairo, 1906-1907/1323-1324; 10 vols. en 5 tomos. 



\section{NOTAS}

(1) Como recoge Federico RUBIO GOMIS: Introducción a la historia altomedieval de Alcoy y su comarca (500-1275), Alcoy, s.e., 1987, pp. 88-89.

(2) Ver al respecto Míkel de EPALZA: «L'estructuració comarcal de la Marina d'Ondara en època àrab (Textos i topónims)», Aiguaits, Alacant, $n^{\circ}$. 10, hivern 1994, pp. 7-11.

(3) Ver de Pierre GUICHARD: «Un toponyme historique de l'ancienne Kura de Tudmir: Benicadell», Murgetana, Murcia, ed. Academia Alfonso X el Sabio, $n^{\circ} .45$, 1976, pp. 37-47.

(4) Como ejemplo citaremos el estudio de Joaquín NAVARRO REIG: «Los mudéjares contestanos en el siglo XIII», Historia Medieval. Anales de la Universidad de Alicante, Alicante, ed. Universidad de Alicante, $\mathrm{n}^{\circ}$. 6, 1987, pp. 175-206, trabajo específico al que habrian de añadirse muchos otros de Robert I. BURNS, Maria Teresa FERRER I MALLOL, José HINOJOSA MONTALVO, Primitivo PLA ALBEROLA, R. BAÑO I ARMIÑANA, del propio J. M. del ESTAL, etc., lista de enumeración demasiado larga.

(5) Entre la abundante bibliografia que trata de la revuelta de Ibn Al-Azraq, sin ánimo de exhaustividad, son de cita obligada los estudios de: $M^{a}$. Carmen BARCELO TORRES: "Documentos árabes de Al-Azraq», Saitabi, Valencia, ed. Universidad de Valencia, $n^{\circ}$. 32, 1982, pp. 27-41; Robert I. BURNS; Paul E. CHEVEDDEN: «EI tractat de rendició d'Al-Azraq amb Jaume I i l'infant Alfons en 1245: el text àrab i el context valencià», L'Espill. Homenatge al Professor Miguel Sanchis Guarner (1911-1981), Valencia, n. 17-18; Ibid:: «Al-Azraq's surrender treaty with Jaume I and Prince Alfonso in 1245: Arabic text and Valencian context", Der Islam. Zeitscrift für Geschichte und Kultur des Islamischen Orients, Berlín, Baud 66, Helft 1, 1989, pp. 1-37. R. I. BURNS: «The Crusade aganist Al-Azraq: a thirteenth-century mudejar revolt in international perspective», The American Historical Review, Philadelphia, vol. 93, $n^{\circ}$. 1, 1988, pp. 80-105; ibid"«Warrior Neighbors: Alfonso el Sabio and Crusader Valencia, an Archival Case Study in his International Relations", Viator. Medieval and Renaissance Studies, Berkeley, Los Angeles, ed. University of California Press, $n^{\circ} .21,1990$, pp. 147-202; R. BAÑO ARMIÑANA: "Contribució a l'estudi de lews sublevacions d'Al-Azraq en les comarques de l'Alcoià i del Comptat", Revista del Instituto de Estudios Alicantinos, Alicante, ed. Instituto de Estudios Alicantinos, 1981, $n^{\circ} .33$.

(6) Míkel de EPALZA: "Cocentaina en los textos árabes», Festes de Moros $i$ Cristians a Sant Hipòlit, Cocentaina, ed. Ajuntament de Cocentaina, 1987 agost, 2 pp., y en «L'ordenació del territori del País Valencià abans de la conquesta, segons Ibn Al-Abbar (segle XIII)), Sharq Al-Andalus. Estudios Árabes, Alicante, ed. Universidad de Alicante, $n^{\circ}$. 5, 1988, pp. 41-67, estudio esencial para conocer el Levante de la Península lbérica en el periodo almohade.

(7) AL-'UDRT: Tarsī al-ajbār, ed. ár. de 'Abd Al-'AzİZ AL-AHWĀNİ, p. 20.

(8) La traducción del fragmento es la que sigue: «Qusantåna: Castillo (hisn) maravilloso, dependiente (min 'amâl) de Denia, en Al-Andalus. De ella (es originario) Abu $1-W a / T$ Ibn Jamis Al-QusantanT, uno de los visires de los Banü

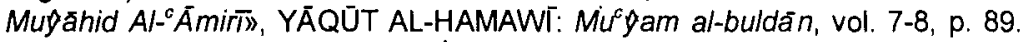


(9) IBN AL-ABBÄR: Takmilat li-Kitāb as-sila, ed. F. CODERA Y ZAYDÍN, pp. $338,187-8$ y 724 .

(10) IBN AL-ABBĀR: Al-Mư ̧am, ed. de F. CODERA Y ZAYDÍN, p. 157; biografía $n^{\circ} .137$

(11) IBN AL-JATĪB: Al-Ihătat fi ajbăr Garnăta, ed. de Muhammad 'Abd Allăh 'INĀN, vol. IV, pág. 239.

(12) AL-MAQQARI': Nafh at-tỉb min gusn Al-Andalus al-rațb, ed. Insăn ${ }^{\mathrm{C} A B B A ̄ S}$, vol. II, p. 506.

(13) Ver de $M^{a}$. Jesús RUBIERA: La Taifa de Denia, Alicante, ed. Instituto "Juan Gil Albert", 1985, 172 pp. Míkel de EPALZA: «Notas sobre el lingüista lbn Sidah y la historia de Denia y su comarca», Revista del Instituto de Estudios Alicantinos, Alicante, $\mathrm{n}^{\circ}$. 33, 1981, pp. 161-172; «Importancia de la historia árabe de Denia», Dianium, Denia, n. 1, 1982, pp. 45-89; «El esplendor de Al-Andalus, reflejo del esplendor fatimi en el siglo XIN», Actas del IV Coloquio Hispano-Tunecino (Palma de Mallorca), Madrid, ed. I.H.A.C., 1983, pp. 79-82. El ambiente socio-cultural del área interior valenciana se estudia en el libro de $M^{a}$. J. RUBIERA y $M$. de EPALZA: Xàtiva musulmana (segles VIII-XIII), Xàtiva, ed. Ajuntament de Xàtiva, 202 pp.

(14) YĀQŪT AL-HAMAWĨ: Mựam al-buldān, ed. A. AMĪN AL-JĀNAȲ̄ et alii, vol. $7-8$, p. 89 .

(15) IBN AL-ABBĀR: Takmilat li-Kitāb as-sila, ed. de F. CODERA Y ZAYDÍN, $n^{\circ}$. 653; ed. de ${ }^{C} A$. AL-ATTĀR, $n^{\circ}$. 1296. Ibn Ál-Abbár en Al-Múyam aporta una biografía ( $n^{\circ}$. 137) de este adíb algo cambiada: en cuanto al nombre (Abü 'Āmir Muhammad Ibn Ismāi Ibn Muhammad Ibn 'Abd Al-Malik 'Abd Ar-Rahmān Ibn Umayya Ibn Satraf (?) Ibn Jamî́s), al topónimo de origen («min ahl Qusantăniya, "amal de Dániyà)), y listado de maestros.

(16) Sobre los calígrafos, ver J. RIBERA Y TARRAGO : «Escuela valenciana de calígrafos árabes», Disertaciones y Opúsculos. Edición colectiva que en su jubilación del Profesorado le ofrecieron sus discipulos y amigos [1887-1927], Madrid, vol. II, 1928, pp. 304-308.

(17) IBN AL-ABBÁR: Takmila, ed. ár. de 'A. AL-ATTĀR, biografía n. 1638.

(18) Es Abū Ya $a^{c}$ far Ahmad Ibn 'Abd Allăh Ibn Jamīs Ibn Mu'awiyya Ibn Nasrūn Al-Azdi, IBN AL-ABBĀR: Takmilat li-Kităb as-sila, ed. de 'A. AL-ATTĀR, n. 161. 1806.

(19) Es Mansūr Ibn Jamīs Ibn Muhammad Ibn Ibrăhīm Al-Lajmī, Ibidem, $\mathrm{n}^{\circ}$.

(20) Ver sobre la misma los estudios de Jacinto BOSCH VILA: «Notas de toponimia para la historia de Guadalest y su valle. A propósito de unas correcciones a un pasaje de la edición del Kitāb al-marqaba al-culyã de al-Nubāhi», publicado originalmente en Miscelánea de Estudios Arabes y Hebraicos (Granada, vol. XIV$X V$, fasc. $1^{\circ}, 1965-66$, pp. 47-74) y reimpreso en Sharq Al-Andalus. Estudios Árabes, Alicante, $n^{\circ} .3,1986$, pp. 201-230. $\mathrm{M}^{\mathrm{a}}$. Isabel CALERO SECALL: "Los Banū Sid Būna", Sharq Al-Andalus. Estudios Árabes, n. 4, 1987, pp. 35-44.

Posterormente los he estudiado en dos trabajos: «ldentificación de la tumba de los STd Bono en Benifato (Alicante)", Sharq Al-Andalus. Estudios Árabes, Alicante, $\mathrm{n}^{\circ}$. 5, 1988, pp. 181-186 y «Andalusies y magrebies en torno a los Sid Bono/a de Guadalest y Granada», Actas del I/ Coloquio Hispano-Marroqui de Ciencias Histori- 
cas "Cultura, Ciencia y Sociedad», Granada, 6-11 noviembre 1989, Madrid, ed. I.C.M.A./Al-Andalus'92, 1992, pp. 217-232.

(21) Esta lápida fue traducida por el arabista valenciano como sigue: «En el nombre de Alá clemente y misericordioso señor nuestro. jOh, hombres (acordaos de) que las promesas de Alá son verdaderas; no os alucine (con sus falsas apariencias) la vida presente, ni os ciegue la ilusión hasta olvidar los beneficios de Dios. Este es el sepulcro de Mohámed ben Abdala ben Cid Bono El Ansari que ha profesado la fe (y ha dado testimonio) de que no hay más Dios que Alá, único, sin asociado (que sea Dios con él), que Mahoma fue su Siervo y Profeta, que hay cielo e infierno y que la hora (final) de la justicia en el dia de la resurrección ha de venir, no cabe duda.

Murió (en el Señor), Alá le tenga misericordia y perdone (sus pecados), la noche del jueves primer día del chumada primero del año 453. Alá te sea clemente», Julián RIBERA: "Historia árabe valenciana», en Disertaciones $y$ Opúsculos, Madrid, Imp. de Estanislao Maestre, vol. II, 1928, pp. 264-266.

(22) A pesar de la coincidencia en el nombre, $M^{a}$. Isabel CALERO afirma la pertenencia de este STd Bono a otra rama diferente, por el apelativo Al-Ansăñ, diferente de la Al-JuzăT del resto de los personajes citados, «Los Banú Sid Būna», p. 36. Ambos apelativos no son excluyentes.

(23) IBN AL-ABBĀR: Takmilat li-Kitab as-sila, ed. 'A. AL-ATTĀR, n. 156; breve biogrfía en la ed. ár. de Alfred BEL; M. BEN CHENEB: $n^{\circ} .156$.

(24) IBN AL-ABBĀR: Takmilat li-Kitáb as-sila, resumido en la ed. de F. CODERA Y ZAYDIN, biografía $n^{\circ}$. 2051, y bastante más extensa en las adiciones realizadas en la ed. de M. ALARCÓN y Á. GONZALEZ PALENCIA. IBN AZ-ZUBAYR: Silat as-silat, ed. ár. de E. LEVI-PROVENÇAL, p. 188. M". I. CALERO: "Los Banu STd Būnà», p. 37.

(25) IBN AZ-ZUBAYR: Silat as-silat, ed. ár. de É. LÉVI-PROVENÇAL, p. 188. M. I. CALERO: «Los Banü Sìd Būnaì, p. 37.

(26) Erróneamente leyó É. Lévi-Provençal "Wãdt Āš min camal Dăniya" (AN-NUBĀHT: Kitáb al-marqabat al-culyă', p. 136) en vez de Wādí Lašt, como luego corrigiera J. Bosch Vilá: "Notas de toponimia ...», pp. 203 y ss.

(27) Abu Madyan Sucayb Ibn Al-Husayn fue uno de los grandes místicos del Islam, también maestro de Ibn 'ArabT. Fue de los fundadores de la escuela šádiiT, tarīqa süft una de cuyas ramas será la de los STd Bono, ver G. MARÇAIS, s.v. en la $E . I^{2}$., vol. I, pp. 141-142.

(28) Los datos biograficos que de este personaje recogió en su obra Ibn AlAbbarr son los siguientes: "Ya far Ibn ${ }^{\circ} A b d$ Allah Ibn Muhammad Ibn Sid Bono AlYuzáT Al- ${ }^{\circ} \bar{A}$ bid, de familia de Cocentaina, demarcación de Denia; con kunya Abū Muhammad. Aprendió lecturas coránicas de Abu Hudayl y fue discipulo oficial suyo, y (éstudió también) con lbn Na ma en Valencia. Después viajó a hacer la Peregrinación; estuvo en Alejandría y formó parte de los que fueron discipulos de As-Sala$\pi$, pero no figura entre sus discipulos oficiales, por to que he sabido. Volvió a su tierra con inclinaciones hacia la ascética (zuhd) y el desprecio del mundo (al-icrăd 'an ad-dunyá). Fue maestro de mística (sayj al-mutas awwafa) en su tiempo y tuvo alta fama su doctrina religiosa después de muerto, a pesar de no ser sistemática. Le vi cuando vino a Valencia para animar la noche de mitad del mes de ša"bãn del año 611 (10 diciembre 1214). Murió muy anciano, de casi 100 años, mediado el 
mes de Du-l-qa'da de 624 (27 octubre 1227), haciendo la profesión de fe. A su encuentro vino muchisima gente de todas partes, y durante mucho tiempo la gente venia regularmente a su tumba para sacar bendiciones de visitarla. Hasta que vino la ocupación de los cristianos sobre los musulmanes que vivian en esas tierras del Levante, cuando la conquistaron, el mes de ramadán de 645 (30 diciembre 1247-28 enero 1248)». IBN AL-ABBĀR: Takmilat li-Kităb as-sila, ed. de 'A. AL-ATTĀR, n'. 643; igual en la ed. ár. de Alfred BEL; M. BEN CHENEB: $n^{\circ}$. 643. Su biografía también la recoge IBN AL-JATİB: /hăta, ed. ár. de M. 'A. A. 'INĀN, vol. I, pp. 461-3.

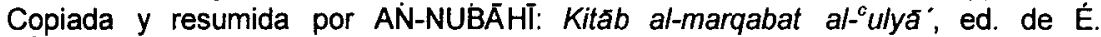
LÉVI-PROVENÇAL, p. 137. Mª. I. CALERO: "Los Banū ST̃d Būna», p. 38-39.

(29) Abu Tăhir Ahmad Ibn Muhammad Ibn Ahmad Ibn Muhammad Ibn Ibrăhīm Silafa As-SilafT, fue uno de los grandes maestros del Islam en la ciencia de las tradiciones. Autor de numerosas obras, viajó continuamente, aprendiendo las ciencias de la religión, hasta que se asentó definitivamente en Alejandría, donde se dedicó a eseñarlas. Murió en 575/1179-80.

(30) Dato tomado de la Sila de Ibn Az-Zubayr por Ibn Al-Jatib: Ihăta, I, p. 462.

(31) Preferimos la fecha de muerte de Ibn Al-Abbar -que lo conoció- a la que da Ibn Al-Jatib de šawwăl del 624 (14 septiembre-12 octubre 1227), Ihăta, ed. ár. de M. 'A. A. 'IINĀN, vol. I, p. 463.

(32) Los restos materiales del mausoleo han sido dados a conocer por Míkel de EPAZA: "La tumba de un santo musulmán en Benifato", Alcoy, Alcoy, abril 1988, 264-265 y Francisco FRANCO SÁNCHEZ: "La familia de los STd Bono: unos santos árabes de Guadalest", Alcoy, Alcoy, abril 1988, pp. 262-263, Id.: "Identificación de la tumba de los STd Bono en Benifato (Alicante)", Sharq Al-Andalus. Estudios Árabes, Alicante, $\mathrm{n}^{\circ} .5,1988, \mathrm{pp} .181-186$.

(33) AN-NUBĀHT: Kitab al-marqabat al- ${ }^{c} u l y a^{\prime}$, ed. É. LÉVI-PROVENÇAL, p. 126. IBN AL-JATİB: Ihăta, ed. ár. de M. ' ${ }^{\mathrm{A}}$. A. 'INÄN, vol. I, p. 463.

(34) AN-NUBĀHī: Kitāb al-marqabat al- ${ }^{c} u l y a ̄ '$, ed. É. LÉVI-PROVENÇAL, p. 136. IBN AL-JATĪB: Ihăta, ed. M. 'A. A. 'INĀN, vol. I, p. 463; IV, p. 239; este autor granadino ya define el origen de $Y$ a'far Ibn Ahmad Ibn 'A min ahl rabad Al-Bayyazin, esto es, con origen familiar entre las gentes del arrabal del Albaicin. Ibid., I, 459.

(35) Su biografia: "Sus ascendentes y su vida: Eran sus antepasados de Bona -en la región de Ifrīiya-. Su abuelo inmigró a Al-Andalus, a la alquería de Zanita, de Wădĭ Lastat, en el Šarq Al-Andalus, en la circunscripción de Cocentaina ('amal Qusantániya), obteniendo de ella abundantes rentas (ămwălā). Cuando se manifestó su nieto, Abu Ahmad, como cabeza de los que aman a Dios (šayj almurTíin) de esta comarca, se evidenciaron con él sus bendiciones (barakăt). Dió testimonio con su gobierno prestigioso, generoso en baraka. Se exalta de ellos su fama, hasta que se apoderó el enemigo de aquellas zonas. Después murió el šayj ¡Esté Dios satisfecho de él!-y su descendencia emigró a Granada, tras haberse establecido en la ciudad de Elche (madinat Ālš). Se instalaron en el barrio conocido como arrabal del Albaicín (Al-Bayyăzin), separándose y extendiéndose, adoptándolo como casa residencial, dispersándose en él su grupo libremente. Sus seguidores se les incorporaban de los grupos de las gentes del levante (ahl aššarq). Sucedieron a este jeque (šayj) posteriormente otros jeques (šayjā), jefes (yúsūbā), jueces (qãdiyā) y secretarios (jafî̉ā) de entre ellos, tras su muerte - 
¿Dios de apiade de éll-.

Se destacó entre sus semejantes porque fue: mistico según las normas (sunan) de la gente virtuosa (sălihiyīn), de la gente perseverante (ahl al-yalada), respetada (乌adda, encaminada), y poderosa (wa-l-quwwat wa-r-ruyulat, poderosa y viril); por su preferencia y constancia en el ribat. Necesitaba del gihad. Fue buen mixtificador (aš-šayaba), gran imitador (at-tajallaq). Congregó a los humildes, habitualmente forasteros, siendo generoso con los hombres. Fue: solidario, disidente (răfidā) de las falsedades, escaso en el comer y en el vestir. Pervivió entre las élites poderosas y fue digno de confianza de los palacios de los reyes excelsos.

Jeques sucesores: Asumirá el cargo de su padre $A b \bar{C}^{\circ} A \pi$. Tras su muerte, el de secretario (jatib) Abu-l-Hasan Ibn Fadma y otros de entre ellos

Obras: Compuso una famosa obra de prohibición (tahrim) de la pluma, de las polainas y de la flauta. Por éste camino siguieron sus seguidores.

Nacimiento: En dū-l-qa $a^{c} d a$ del 653 (2 a 31 diciembre 1255). Su muerte: Murió el 10 de sawwăl del 733 (24 junio 1333). Fue mucha concurrencia a su entierro y fue de excepcional descripción. Fue enterrado en su cementerio (familiar). 》, IBN AL-JATīB: Ihăta, ed. M. 'A A. 'INĀN, vol. IV, pp. 239-240.

También Ibn Al-Jatib afirma que el cabeza de la cofradia mistica, además de desempeñar un importante cargo honorifico, era designado «para presidir la oración o el sermón, dirigir la comunidad de la iráda de su cofradía y dictaminar en asuntos legales bajo la supervisión del primer juez de la capital», lhăta, I, pp. 459-461.

(36) IBN AL-JATīB: Ihăta, ed. M. 'A. 'INAN, vol. I, pp. 459-461. Sobre el potencial económico que centralizaban estas tarīaat ver $M^{\mathrm{a}}$. Jesús RUBIERA MATA: «Un aspecto de las relaciones entre la Ifríqiya hafsi y la Granada nas ri: La presencia tunecina en las tariqaát místicas granadinas", Les Cahiers de Tunisie, Túnez, vol. XVI, n. 103-104, 1978, pp. 165-172.

(37) En una Granada superpoblada abundaron las cofradias místicas; entre ellas, la de los STd Bona parece que fue de las más extravagantes e influyentes, $M^{a}$. Jesús RUBIERA MATA: «Datos sobre una "madrasa" en Málaga anterior a la nasrī de Granada», Al-Andalus, Madrid-Granada, $X X X V / 1,1970$, pp. 223-226, e Ibri Al-Yayyáb, el otro poeta de la Alhambra, Granada, ed. Patronato de la Alhambra / I.H.A.C., 1982, p. 47. F. FRANCO: "Andalusies y magrebies ...», p. 222.

(38) $M^{a}$. I. CALERO SECALL: "Los Banū ST̃d Bona», p. 41. L. SECO DE LUCENA: "La escuela de juristas granadinos del siglo XV", Miscelánea de Estudios Árabes y Hebraicos, Granada, $\mathrm{n}^{\circ}$. VIII, 1959, pp. 22-23.

(39) Su función dentro del cadiazgo ha sido matizada por $\mathrm{M}^{\mathrm{a}}$. I. Calero, afirmando que únicamente tenian jurisdicción en los asuntos legales de los miembros de su propia cofradia, «Los Banū STd Bona», pp. 41-42.

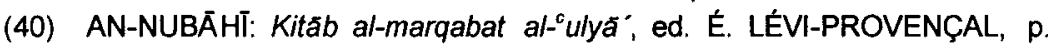
136; IBN AL-JATİB: Ihăta, ed. ár. de M. ' A. A. 'INĀN, vol. IV, p. 2.39.

(41) IBN AL-ABBĀR: Takmilat li-Kitáb as-sila, ed. de 'A. AL-ATTAR, biografias $n^{\circ} .309,1478$; ed de F. CODERA biografias' $n^{\circ} .1806,1712$.

(42) Ver el artículo a él dedicado por É. LÉVI-PROVENÇAL en la E.I ${ }^{2}$, vol. I, pág. 1125.

(43) Míkel de EPALZA: "El Cid = El León: ¿Epíteto árabe del Campeador?", Hispanic Review, Filadelfia, vol. 45, $n^{\circ}$. 1, 1977, pp. 67-75, reed. en Sharq Al-Anda- 
lus. Estudios Árabes, Alicante, n. 7, 1990, pp. 227-236. Ampliación en «Etimología árabe del Cid, como antropónimo ("El León") y como topónimo ("El señor y/o gobernador almohade")", Sharq Al-Andalus. Estudios Árabes, Alicante, n. 7, 1990, pp. 157-169; «Topònims d'origen antroponímic àrab de temps de la conquesta (Cid, Busot, Benimassot, Massoda, Benissoda, Benissaudet)", Actes del Catorzè Col/loqui General de la Societat d'Onomàstica (Segon d'Onomàstica Valenciana). Alacant 13-15 d'abril de 1989, Alacant, vol. II, 1991, pp. 619-627. Ver también Míkel de EPALZA; Suzanne GUELLOUZ: Le Cid, Personnage historique et litteraire, París, ed. G.-P. Maisonneuve et Larose, 1983, pp. 10-11.

(44) IBN HAYYĀN: Muqtabis VI, trad. esp. de E. GARCIA GÓMEZ: Anales

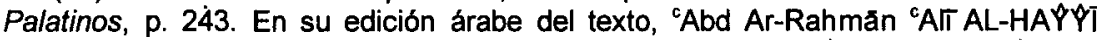
lee erróneamente "Surür Ibn Funuh" (Al-Muqtabas fá ajbăr bilad Al-Anidalus (Al-Hakam II), Bayrūt (Libano), 1965, p. 203).

(45) Maria Jesús RUBIERA; Mikel de EPALZA: Xàtiva Musulmana (segles VIIIXIII), Xàtiva, ed. Ajuntament de Xàtiva, 1987, 202 pp., pp. 72-73. Ver también de los mismos autores: «Los cristianos toledanos bajo dominación musulmana», Simposio Toledo Hispanoárabe, Toledo, 1988, pp. 130-133.

(46) Recogido oralmente por Míkel de Epalza, a quien agradecemos el dato.

(47) Ma. J. RUBIERA; M. EPALZA: Xàtiva Musulmana, pp. 75-81.

(48) $M^{a}$. Teresa FERRER I MALLOL: Els sarrains de la Corona Catalanoaragonesa, Barcelona, Institució Milà i Fontanals del C.S.I.C., 1988, 427 pp. Son también de un enorme interés para la comprensión de la historia de los mudéjares alicantinos contemporáneos las obras, complementarias de la anterior, de la misma investigadora: Les aljames sarraïnes de la Governació d'Oriola en el segle XV. Barcelona, Inst. Milà i Fontanals del C.S.I.C., 1988, 338 pp., id.: La frontera amb I'Islam en el segle XIV. Cristians i sarrains al Pais Valencià, Barcelona, Inst. Milà i Fontanals del C.S.I.C., 1988.

(49) $M^{a}$. Teresa FERRER I MALLOL: Les aljames sarraïnes ..., pp. 95-97; Apéndice Documental, docs. $n^{\circ}$. 36, 42, 106, 107.

(50) Pascual BORONAT Y BARRACHINA: Los moriscos españoles y su expusión. Estudio histórico-crítico por ...., Valencia, Imp. Vives y Mora, 1901, vol. I, pp. 443-469.

(51) Ver F. FRANCO SÁNCHEZ: "Andalusies y magrebíes ...", notas 42 a 45.

(52) IBN AL-ABBÃR: Takmilat li-Kităb as-sila, resumido en la ed. de F. CODERA Y ZAYDÍN, biografía $n^{\circ}$. 1935, y más amplia en la ed. de M. ALARCÓN y Á. GONZALEZ PALENCIA.

(53) IBN AL-ABBĀR: Takmilat li-Kitáb as-sila, ed. de 'A. AL-ATTĀR, n. 1346.

(54) IBN AL-ABBĀR: Takmila, ed. de 'A. AL-ATTĀR, n'. 1451.

(55) Ver nota 7.

(56) Ver nota 8.

(57) IBN AL-ABBĀR: Takmila, ed. de 'A. AL-'ATTĀR, ns. 156; 643; 1296; 1346; 1451; ed. de F. CODERA Y ZAYDÍN, ns. 1935; 2051 ampliadas en la ed. de M. ALARCÓN; Á. GONZÁLEZ PALENCIA. En la ed. ár de la Takmila de A. BEL; $M$. BEN CHENEB se vocaliza erróneamente Qustuntăniya en una ocasión (biografía $n^{\circ}$. 156), y en otra, no es vocalizado $\left(n^{\circ} .643\right)$. 
(58) IBN AL-ABBĀR: Al-Múyam, ed. de F. CODERA Y ZAYDINN, $n^{\circ} .137$.

(59) Ver nota 17.

(60) Ver nota 15. 136.

(61) AN-NUBĀHT: Kităb al-marqabat al-'ulyã', ed. É. LÉVI-PROVENÇAL, p.

(62) Ver J. BOSCH VILA: «Notas de toponimia ...», pp. 205-206.

(63) Ver nota 35.

(64) Ver nota 12.

(65) Como lo indica (a modo de sondeo) el que en el Llibre del Reapartiment de València aparezca Cocentaina con las siguientes variantes: Colzentania, Colzontania, Coçoltania, Consoltaina, Consoltania, Cosoltania, además de un rivus Colzontania. Llibre del Repartiment de València, ed. A FERRANDO I FRANCÉS et alii, València, Vicent García Editores, 1978, pp. 181-182 e "Index" final. Como en el caso de los topónimos árabes, la frecuencia de la metátesis del nombre es la causante de tantas variantes, antes y después de la conquista cristiana.

(66) M. de EPALZA: «L'ordenació del territori ...», pp. 42-51.

(67) Ibidem, pp. 54-55.

(68) Ver F. RUBIO: Introducción a la historia ..., pp. 61-66.

(69) Ver $M^{a}$. Jesús RUBIERA: Villena en las calzadas árabe y romana, Alicante, ed. Ayuntamiento de Villena / Universidad de Alicante, 1975.

(70) $M^{\circledR}$. Jesús RUBIERA: «Els camins àrabs de la muntanya i la Marina alacantines $\mathrm{i}$ una hipòtesi sobre el nom d'Alcoi», Societat d'Onomàstica. Butlleti Interior. XIVé. Colloqui. Alacant. (13-15-IV-1989), València, $n^{0}$. 44, 1991 març, pp. 671-672; íbid. «Los caminos árabes de la comarca de la Marina Alta», $1{ }^{\text {on }}$ Congrés d'Estudis de la Marina Alta, Denia, 1984. 